\title{
Promoção da saúde do idoso: desafios contemporâneos para a administração pública municipal
}

\author{
Wiliam César Alves Machado, D.Sc.*, Nébia Maria Almeida de Figueiredo, D.Sc.**, \\ Rodrigo Sousa de Miranda***, Carla Oliveira Shubert ${ }^{* * *}$, Queila Gaudino*****
}

\begin{abstract}
*Enfermeiro, Professor e Orientador Acadêmico no Programa de Pós-Graduaçâo-Mestrado em Enfermagem da Escola de Enfermagem Alfredo Pinto, Universidade Federal do Estado do Rio de Janeiro - UNIRIO, **Enfermeira, Professora Titular do Departamento de Enfermagem Fundamental da Escola de Enfermagem Alfredo Pinto da Universidade Federal do Estado do Rio de Janeiro - UNIRIO, Professora e Orientadora nos Programas de Pós-Graduação - Mestrado e Doutorado em Enfermagem, da Escola de Enfermagem Alfredo Pinto, da Universidade Federal do Estado do Rio de Janeiro - UNIRIO, ${ }^{* * *}$ Enfermeiro, Mestrando no Programa de Pós-Graduação - Mestrado em Enfermagem da Escola de Enfermagem Alfredo Pinto da Universidade Federal do Estado do Rio de Janeiro, UNIRIO, ***Enfermeira, Mestranda no Programa de Pós-Graduação - Mestrado em Enfermagem da Escola de Enfermagem Alfredo Pinto da Universidade Federal do Estado do Rio de Janeiro, UNIRIO, Enfermeira, Prefeitura Municipal de Três Rios, Secretaria Municipal do Idoso e da Pessoa com Deficiência de Três Rios, Centro Dia para Idosos
\end{abstract}

\section{Resumo}

Objetivos: Descrever como idosos usuários de políticas públicas de saúde percebem mudanças no seu dia a dia, decorrentes dos atendimentos intersetoriais prestados na unidade Planeta Vida. Método: Estudo exploratório-descritivo, com enfoque qualitativo, realizado no período de maio e junho de 2011, com 28 pessoas com 60 anos ou mais. O instrumento para coleta de dados foi um questionário, com perguntas sobre as alteraçóes percebidas entre o antes e o após frequentar a unidade. Resultados: Os idosos perceberam mudanças significativas no dia a dia após frequentar a unidade, passando de vida sedentária e sem perspectiva, para vida mais participativa, com novo horizonte, resgate da autoestima e sensaçáo de melhor qualidade de vida. Conclusão: Conclui-se que os atendimentos pautados na perspectiva intersetorial contribuem para a inclusão, resgate da autoestima, autonomia, promoção da saúde para que as pessoas desfrutem de um envelhecimento saudável.

Palavras-chave: envelhecimento, promoção da saúde, políticas públicas, cuidados de saúde.

\section{Abstract \\ Health promoting of elderly: contemporary challenges for municipal public administration}

Objectives: To describe how elderly users of health public policy perceived changes in their daily living activities due to care provided in the unit - Planeta Vida. Method: This was a descriptive exploratory study, with a qualitative approach, carried 
out from May to June 2011, with 28 elderly aged 60 or more. The instrument for data collection was a questionnaire, with questions about perceived changes before and after attending the unit. Results: The elderly perceived significant changes from day to day after attending in the unit, from a sedentary life to a more participating life, with new horizons, rescuing the selfesteem and sensation of better quality of life. Conclusion: The treatment inserted into this perspective greatly contributes to inclusion, self-esteem recovery, autonomy, health promotion, for elderly enjoying a decent and healthy aging.

Key-words: aging, health promotion, public policy, health care.

\section{Resumen}

\section{Promoción de la salud de los ancianos: desafíos contemporáneos de la administración pública municipal}

Objetivo: Describir cómo los usuarios de políticas Públicas de Salud con edad avanzada se dan cuenta de los cambios en su día a día, derivados de los cuidados intersectoriales ofrecidos en la unidad - Planeta Vida. Método: Estudio exploratoriodescriptivo, con enfoque cualitativo, realizado de mayo a junio 2011, con 28 ancianos con 60 años o más. El instrumento de recolección de datos fue un cuestionario, con preguntas acerca de los cambios percibidos entre antes y después de haber sido asistido en la unidad. Resultados: Los ancianos perciben cambios significativos en el día a día después de asistidos en la unidad, de una vida sedentaria y sin perspectivas para una vida más participativa, con nuevos horizontes, con rescate de la autoestima y el sentido de nueva calidad de vida. Conclusión: Se concluye que los tratamientos guiados por una perspectiva intersectorial contribuyen en gran medida para la inclusión, la recuperación de la autoestima, la autonomía, la promoción de la salud, para que las personas desfruten de un envejecimiento digno y saludable.

Palabras-clave: envejecimiento, promoción de la salud, políticas públicas, cuidados de salud.

\section{Introdução}

O Planeta Vida constitui-se unidade da administração pública municipal de Três Rios, na regiáo Centro Sul do Estado do Rio de Janeiro. Foi implantado em maio de 2009 com propósitos de oferecer serviços e atendimentos com implicaçóes intersetoriais, para dar conta da diversidade de elementos envolvidos nas necessidades de saúde e inclusão social de idosos de limitado poder aquisitivo e excluídos dos serviços oferecidos na rede privada. $\mathrm{Na}$ unidade, idosos podem ser atendidos gratuitamente nos programas de reabilitação física e sensorial, promoção da saúde, inclusão digital, ginástica e condicionamento físico, hidroginásti$\mathrm{ca}$, hidroterapia, entre outros, que lhes concedem oportunidade de transformar suas vidas para um envelhecimento saudável.

O desafio maior no século XXI, no Brasil, será cuidar de uma populaçáo de mais de 32 milhóes de idosos, a maioria com baixo nível socioeconômico e educacional, e com alta prevalência de doenças crônicas e incapacitantes [1-2]. Com o crescimento progressivo do número de idosos, o Brasil deve passar, no período de 1960 a 2025, da décima sexta para a sexta posição mundial em relação a esse contingente populacional. Trata-se de resultado da queda das taxas de fecundidade e mortalidade e do consequente aumento da expectativa de vida [3].

Diante do que se anuncia, cabe destacar a oportuna crescente tendência global de descentralização das políticas sociais e, consequentemente, de descentralização e municipalização de recursos e programas. No Brasil, o processo de descentralizaçáo, iniciado nos anos 1980, tem uma estreita relação com os processos de democratização política [4]. Essa descentralização política oferece perspectivas interessantes, em particular pelo fato de que as políticas locais podem integrar os diferentes setores e articular os diversos atores. Ademais, o papel desempenhado pelas autoridades locais, ou gestores sociais, passa a ter uma importante função na definição de políticas e na execução de programas que beneficiam a populaçáo da cidade.

Nesse contexto, destaca-se o papel do Planeta Vida, como espaço inclusivo que exprime sintonia de gestores públicos municipais da região Centro Sul Fluminense, no qual amplo espectro de procedimentos intersetoriais disponíveis para que idosos tenham acesso a mudanças substantivas no seu dia a dia. Serviços e atendimentos intersetoriais que envolvem profissionais das Secretarias Municipais do Idoso e da Pessoa com Deficiência, Esportes e Lazer, Saúde e Defesa Civil, e Educação, de Três 
Rios, convergindo esforços voltados para assegurar aos idosos o melhor em termos de promoção da saúde e inclusão social [5].

A unidade oferece atmosfera mágica capaz de atrair as pessoas como imã, amalgamando esperanças, envolvendo-as num bailado que confunde o inverossímil e o verossímil. Muitos chegam cedo, antes mesmo do amanhecer, ainda que no intenso frio das madrugadas na regiáo Centro Sul Fluminense, apenas para garantir presença e satisfação de compartilhar com seus pares mais um dia de experiências transformadoras, embora todos os atendimentos sejam previamente agendados [5]. Apesar dessa atmosfera promissora é preciso captar a impressão dos seus usuários, com vistas no aprimoramento do programa. A partir daí surgem as seguintes questóes de pesquisa: Como era e o que mudou na vida dos idosos com os atendimentos no Planeta Vida? ; e O que é preciso fazer para melhor atender aos usuários na unidade?

A propósito do subjacente compromisso da equipe para com os usuários da unidade, vale destacar que a implementação de políticas sociais com enfoque intersetorial implica na superação de açóes fragmentadas e o privilégio dado a projetos articulados, com o compartilhamento de informaçóes e permeáveis à participação do cidadão, tanto no planejamento quanto na avaliação de açóes e serviços [4].

Neste estudo, compreende-se promoção da saúde como o processo de capacitaçáo dos idosos para assumir maior autonomia nas atividades cotidianas e, consequentemente, desfrutar de melhor qualidade de vida. Para atingir um estado de completo bem estar físico, mental e social, os indivíduos e grupos devem saber identificar aspirações, satisfazer necessidades e modificar favoravelmente o meio ambiente [6].

A OMS recomenda que políticas de saúde na área de envelhecimento levem em consideração os determinantes de saúde ao longo de todo o curso de vida (sociais, econômicos, comportamentais, pessoais, culturais, além do ambiente físico e acesso a serviços) [7]. É o que se pode identificar naquelas que optam pela adoçáo de estratégias focadas na intersetorialidade, como a do contexto estudado.

Além das políticas públicas instituídas nas três esferas de governo (federal, estadual e municipal) em favor dos idosos, vale ressaltar que, nas últimas décadas, importantes avanços no campo da saúde têm sido conquistados no Brasil. Assim, o processo de construção do Sistema Único de Saúde (SUS), regulamentado pela Constituiçáo Federal de 1988 e pelas Leis Complementares, vem ocorrendo sobre os pilares da universalização, da integralidade, da intersetorialidade, da descentralizaçáo e da participação popular [3].

Com efeito, os fatos e as evidências apontam urgência de mudanças no cuidado à população idosa. Os modelos tradicionais vigentes se mostram ineficientes e de alto custo. Assim, tornam-se necessários novos métodos de planejamento e gerência, pois a prestação dos cuidados reclama estruturas criativas e inovadoras, com propostas de açóes diferenciadas, de modo que o sistema ganhe eficiência e o idoso possa usufruir integralmente os anos proporcionados pelo avanço da ciência [7].

É inegável que o prolongamento da vida é uma aspiração de qualquer sociedade. No entanto, só pode ser considerado como uma real conquista à medida que se agregue qualidade aos anos adicionais de vida [3]. É importante destacar que qualquer política destinada aos idosos deve levar em conta a capacidade funcional, a necessidade de autonomia, de participação, de cuidado, de auto-satisfação [7].

Sabe-se que a utilizaçáo do conceito de promoção da saúde é anterior a Conferência de Ottawa, elaborada em 1986, na qual foi definido como processo de capacitaçáo da comunidade para atuar na melhoria de sua qualidade de vida e saúde, incluindo uma maior participaçáo nesse processo. As definiçóes da Carta de Ottawa evidenciam a expectativa da comunidade internacional por uma saúde pública inclusiva, levando em conta os determinantes do processo saúde-doença-cuidado, na busca por equidade e justiça social. Este documento adota o conceito positivo de saúde, enfatizando que a promoção da saúde não é responsabilidade exclusiva do setor saúde, e vai para além de um estilo de vida saudável, na direção de um bem estar global [8].

Neste aspecto, a promoção da saúde é uma das estratégias para buscar a melhoria da qualidade de vida da população. Seu ideal abarca o fortalecimento da capacidade individual e coletiva em saber conviver com as multiplicidades dos condicionantes da saúde. Este fortalecimento da saúde dá-se por meio da capacidade de escolha, da utilizaçáo do conhecimento com o discernimento de perceber as diferenças e semelhanças dos acontecimentos geradores de saúde ou de doença [9].

A qualidade de vida (QV) e a satisfação na velhice têm sido muitas vezes associadas às questóes 
de dependência e autonomia, sendo importante distinguir os ditos efeitos da idade. Algumas pessoas apresentam declínio no estado de saúde e nas competências cognitivas precocemente, enquanto outras vivem saudáveis até idades muito avançadas [10]. Representa respostas individuais a fatores físicos (objetivos) e mentais (subjetivos) que contribuem para uma vida mais equilibrada, permeada pela satisfação pessoal, autoestima, comparação com o outro, experiências prévias, situação econômica, estado geral de saúde e estado emocional.

Além disso, a QV é considerada uma percepçáo eminente humana que abrange múltiplas definiçóes, influenciada por diversos fatores que não se restringem ao tempo, condiçóes socioeconômicas, culturais e de saúde. Embora não exista um significado consensual, há uma concordância acerca do constructo, cuja característica é ser: multidimensional, relacionando-se ao fato de que a vida compreende múltiplas dimensóes, tais como a social, mental, material, física, cultural, econômica, dentre outras [11].

O que pressupóe a intersetorialidade primordial no trato de questóes que englobam condiçóes e os recursos para a saúde, como paz, habitação, educação, alimentação, renda, ecossistema estável, recursos sustentáveis, justiça social e equidade.

Nessa sintonia, o objetivo deste estudo é descrever como idosos usuários de políticas públicas de saúde percebem mudanças no seu dia a dia, decorrentes dos atendimentos intersetoriais prestados na unidade Planeta Vida.

\section{Material e métodos}

Trata-se de estudo exploratório descritivo com abordagem qualitativa, entendendo que esta oferece ao pesquisador a possibilidade de compreender como as pessoas pensam e reagem diante de questôes que lhes afetam, assim como possibilita uma aproximação da dinâmica e a estrutura da situação em estudo, de acordo com a concepção daqueles que as vivenciam [12]. A pesquisa qualitativa também é entendida como capaz de incorporar a questáo do significado e da intencionalidade como inerentes aos atos, às relaçóes, e às estruturas sociais, sendo estas últimas tomadas tanto no seu advento quanto na sua transformação, como construções humanas significativas [13].

O cenário do estudo foi uma unidade de reabilitação da rede pública municipal de Três Rios/ RJ,
Brasil, pioneira na oferta de modalidades de serviços e atendimentos pautados na intersetorialidade, o que agiliza a resolução de situações e necessidades nas quais idosos teriam de recorrer a uma série de unidades para consulta, avaliaçáo e encaminhamentos profissionais especializados em várias áreas de conhecimento.

Foram sujeitos do estudo 28 idosos com 60 anos ou mais, com escolaridade equivalente ao ensino básico, regularmente inseridos e usuários dos atendimentos da unidade denominada Planeta Vida.

Os critérios utilizados para inclusão dos sujeitos no estudo foram: a) estar regularmente inscrito em serviço da unidade; b) dispor de habilidade e autonomia para responder com escrita individual; c) pessoas com 60 anos ou mais; d) ter nível escolar equivalente ao atual ensino básico e; e) que concordaram espontaneamente em participar da pesquisa. Foram critérios de exclusão: a) ter idade inferior a 60 anos; b) não ser usuário da unidade; c) não ter escolaridade equivalente ao ensino básico e; d) negar-se assinar o termo de consentimento livre e esclarecido.

Foi aplicado um questionário com perguntas abertas, visando à livre associação de ideias por parte do participante, nas instalaçóes da unidade, mediante a assinatura de um termo de consentimento livre e esclarecido, de acordo com as normas da resolução 196/96 que dispóe sobre os aspectos éticos de pesquisa com seres humanos, e após aprovação do Comitê de Ética em Pesquisa da UNIRIO (Parecer CEP-UNIRIO - 268983) [14]

Os dados foram coletados pelos pesquisadores que atuam na unidade, os quais apresentaram aos idosos o questionário, após autorização do participante e mediante garantia de sigilo e do anonimato. Optou-se por identificá-los através das iniciais do nome, sexo e idade, conforme observado na análise dos dados. Foram aplicados 30 (trinta) questionários, sendo que 2 (dois) idosos desistiram de participar por alegar não ter solicitada autorizaçáo prévia do (a) companheiro (a).

Para análise dos dados adotou-se a técnica de análise de conteúdo, que consiste em identificar os núcleos de sentido que compóem a comunicação e cuja frequência de aparição pode significar algo correlato ao objetivo do estudo [15].

\section{Resultados e discussão}

Após a análise dos dados, foram construídas Unidades de Significado (US) que, aproximadas por 
semelhança de significado, deram origem as seguintes categorias: "Vida sedentária e sem perspectiva: $O$ dia a dia antes do Planeta Vida"; "Vida mais participativa e com novo horizonte: mudanças percebidas após frequentar a unidade" $e$; "Acolhida fraterna: bem estar, segurança e satisfação do usuário".

No que diz respeito ao gênero dos participantes do estudo, identificou-se tratar de 19 mulheres (68\%) e 9 homens (32\%). O perfil dos informantes segundo faixa etária revelou 20 (71\%) informantes com idade entre 60 e 69 anos, 7 (25\%) dos informantes na faixa etária de 70 a 79 anos, e 1 (4\%) dos participante com idade entre 80 e 89 anos. Entre os idosos que participaram do estudo 22 (79\%) declararam fazer uso regular de medicamentos, enquanto outros $6(21 \%)$ informaram náo fazer uso de qualquer medicamento.

A avaliação dos serviços, segundo registros dos informantes, mostrou que 18 (64\%) dos idosos do estudo avaliaram os atendimentos como excelentes, com destaque para a forma como os profissionais interagem com a clientela, 9 (32\%) dos idosos consideraram bom o nível dos atendimentos, e 1 (4\%) avaliou como regular a interaçáo dos profissionais da unidade com seus usuários.

Vida sedentária e sem perspectiva: $O$ dia a dia antes do Planeta Vida

O padrão de vida entre os brasileiros de todas as idades permanece cada vez mais baixo, sendo que $2 / 3$ da população vive abaixo da linha de pobreza e em péssimas condições de saúde. A família é a fonte primeira de cuidados, mas as relaçóes familiares estáo mudando cada vez mais em função da modernização. Como resultado, os idosos na maioria das vezes não recebem o cuidado que esperam receber de seus familiares. Existe uma visível falta de oportunidades, para os idosos no Brasil, de poder participar em atividades sociais fora da esfera familiar, fato esse que limita a participação deles em um leque mais amplo de relações sociais [16].

Um efeito negativo a ser considerado na idade avançada é a falta de autoestima, que acontece devido ao reconhecimento, por parte das pessoas idosas, de sua dependência, e causa a percepçáo de uma falta de autonomia e a inabilidade para retribuir ajudas recebidas. Isto pode levar a insatisfação, estresse, e depressão da pessoa idosa. Normalmente essa depressão está também associada com um sentimento de ser uma carga para aquelas pessoas a quem ela ama [17].

Falta de autoestima, sedentarismo, entre outras situaçóes vivenciadas pelos idosos que podem levar à perda da memória. A esse respeito, uma das consequências do envelhecimento mais temidas pelos idosos é o declínio cognitivo. Assim, estudos que investiguem os fatores de risco associados a esse declínio são necessários. Deve-se enfatizar que a função intelectual está fortemente relacionada com a habilidade de desempenhar as atividades de vida diária e, dessa maneira, viver com independência [18].

A esse respeito, os registros dos participantes deste estudo deixam claro suas difíceis experiências cotidianas no antes de frequentar o programa, a saber:

"Monotonia, sem expectativa nenhuma de melhorar." (OGM, M, 67)

"Meu dia era um dia longo, pois meu filho que é especial também ficava o dia todo em casa." (NMR, F, 60)

"Eu vivia como a maioria dos idosos, sem fazer nada, ou melhor, na frente da TV, pois com idade a gente não tem muito ânimo para sair." (AECM, M, 79)

"Eu era a "Maria das Dores" (...) dores no joelho, na coluna, do pescoço para baixo até o Cox. Só queria ficar deitada, tinha uma preguiça fantástica, nem gostava de caminhar, nem sair de casa, desanimada...". (NSA, F, 67)

"Triste e abandonada, assim que eu me sentia." (MMAS, F, 63)

"O dia era triste e vazio." (MJCR, F, 71)

"Eu me sentia uma pessoa muito desanimada pra baixo mesmo." (LABA, F, 61)

"Eu ficava em casa a toa sem fazer nada." (AJ, M, 68)

"Era sedentária (preguiçosa)" (SRMM, F, 60)

"Ansiedade e depressão." (MHC, F, 64) 
"Era meio complicado, pois acabamos caindo na velha rotina, (...) ir pra praça jogar baralho (...) ficar o dia inteiro sentado num banco de cimento..." (GRG, M,63)

"Sem nenhuma perspectiva ficava de um lado para o outro, só pensando nos problemas que não são poucos (....).” (DCT, F, 60)

A condição prevalente de sedentarismo observada na população em geral, notadamente nos mais idosos, representa uma séria ameaça para o organismo, estimulando o surgimento de doenças crônico-degenerativas, transtorno de humor, diminuindo as funçóes fisiológicas e cognitivas, provocando imunossupressão, piora do perfil lipídico, glicêmico e da qualidade do sono. Além disso, o sedentarismo diminui a autoestima, aumentando a ansiedade; podendo ainda contribuir para o agravamento de quadros de depressão [19].

Além de se perceber ociosos, deprimidos, abandonados, os idosos brasileiros convivem com medo de violências, falta de assistência médica e de hospitais e escassas atividades de lazer, além de angústias com os baixos valores das aposentadorias e pensóes. Apesar do substancial aumento desses valores nos últimos anos, e os valores ainda serem reconhecidamente pequenos, já se observam reflexos positivos, conforme indicado na Pesquisa Nacional por Amostra de Domicílios (PNAD) [20].

Com efeito, a depressão é a doença psiquiátrica mais comum entre os idosos, frequentemente sem diagnóstico e sem tratamento. Ela afeta sua qualidade de vida, aumentando a carga econômica por seus custos diretos e indiretos e, pode levar a tendências suicidas [21]. A depressão é um dos maiores problemas de saúde pública do mundo [22], devido à sua alta morbidade e mortalidade. Sua incidência é estimada em aproximadamente $17 \%$ da população mundial.

Vida mais participativa e com novo horizonte: mudanças percebidas após frequentar a unidade

O envelhecimento populacional é um fenômeno mundial e, no Brasil, as modificaçóes se dão de forma radical e bastante acelerada, processo que, do ponto de vista puramente demográfico, deve-se unicamente ao rápido e sustentado declínio da fecundidade. As projeçōes mais conservadoras indicam que em 2020 já seremos o sexto país do mundo em número de idosos, com um contingente superior a 30 milhóes de pessoas $[2,16]$.

Segundo a Organização Mundial de Saúde, desde 1986, após a divulgação da carta de Otawa, o conceito de promoçáo de saúde é definido como um processo de capacitaçáo da comunidade para melhorar suas condições de vida e saúde. Seu significado contém uma combinação de açôes: do Estado nas suas políticas públicas de saúde; da comunidade, com o reforço das açôes comunitárias; dos indivíduos, com o desenvolvimento das habilidades; de reorientação das intervençóes para açôes conjuntas intersetoriais $[3,20]$.

No concernente às constataçôes de mudanças no dia a dia percebidas pelos idosos após frequentar o Programa, destacam-se:

"Minha vida mudou bastante, sou mais ativo. Antes não tinha o que fazer, agora estou mais interessado em participar. Vida nova." (JBES, M, 66)

"Melhorou muito, faço fisioterapia, andava até de muletas... " (ZS, F, 80)

"Mudou tudo. Agora saio mais, tenho mais ligaçôes com as pessoas. Eu era muito desanimada." (MAMA, F, 75)

"Depois que passei a fazer atividade física, virei outra, demorou seis meses, mas fiquei nova outra vez (...) hoje eu danço, eu caminho uma hora por dia, três vezes na semana, eu viajo para qualquer lugar, sem problema nenhum, durmo bem durante o dia, porque eu trabalho a noite, doze horas de plantão todos os dias, de segunda a sábado das $19 \mathrm{hs}$ às 07hs." (NSA, F, 67)

"O aprendizado em manusear o computador abriu novos horizontes." (MJCR, F, 71)

\footnotetext{
"Quando conheci o Planeta Vida após uma visita tomei conhecimento do curso de informática, interessei e fiz minha matrícula no curso. Como eu só sabia ligar o computador e mais nada, cada aula era mais novidade, consegui concluir o primeiro ciclo do estudo e recebemos o diploma numa festa muito bonita." (AECM, M, 79)
} 
"O Planeta Vida moldou nossas vidas, eu sempre digo que aqui é a extensão de minha casa além das atividades físicas. Fazemos algo muito importante que é fazer novas amizades.” (GRG, M)

"É que tenho mais saúde e mais ânimo e coragem." (ECVC, F, 65)

"Esse programa pra mim tornou-se uma obrigação (muito bom), prazeroso.” (SRMM, F, 60)

"Na parte do exercício físico, muito bom a atividade física (musculação, esteira, bicicleta) deu um novo animo no meu dia a dia, sinto-me bem mais disposto para as atividades rotineiras, houve uma melhora visível no meu eu. Melhorou as relaçóes sociais com um novo estado de espírito me sinto rejuvenescido." (MA, M, 70)

O contato com pares aumenta o sentimento de utilidade, talvez porque contatos sociais fora da esfera da família sejam mais voluntários e menos baseados em obrigaçóes sociais, portanto menos desiguais. O suporte social pode exercer um papel essencial promovendo e mantendo a saúde física e mental. Entretanto cada pessoa pode não ter igual acesso a este importante recurso. Existem talvez significantes variaçôes de classe na natureza e na quantidade, em que o suporte social está disponível [17].

Por outro lado, o exercício físico é uma necessidade absoluta para o homem, pois com o desenvolvimento científico e tecnológico advindo da revolução industrial e da revolução tecnológica pela qual passamos, deparamo-nos com elevado nível de estresse, ansiedade e sedentarismo que compromete a saúde de boa parte das populaçóes de países desenvolvidos e em desenvolvimento [19].

\section{Acolhida fraterna: bem estar, segurança e satisfação do usuário}

Os idosos participantes deste estudo perceberam expressivas mudanças em suas vidas a partir do simples fato de serem atendidos com deferência pela equipe do Planeta Vida, o que náo deveria ser exceção, mas regra na gestáo pública. Destacam algumas oportunidades e atendimentos profissionais especí- ficos como emblemáticos ou maiores responsáveis pela melhoria da qualidade de vida (informática), sensação de bem estar, resgate da autoestima e disposição (condicionamento e exercício físico), melhor estabilidade e controle dos sintomas de doenças crônicas como diabetes e hipertensão, entre outras, com distinção para algumas categorias profissionais (promoção da saúde). Ficando evidente, sobretudo, o reconhecimento dos idosos de que o programa tem contribuído para que levem a vida com mais saúde, bem estar, autoestima e dignidade.

Sabe-se de estudos que relacionaram a diminuição da depressão, após 10 meses de exercício físico, com alteraçóes no sistema imunológico. Uma possível explicação para esses resultados seria a liberação de hormônios como epinefrina, norepinefrina, somatotrofina, endorfina e cortisol, que atingem receptores específicos situados nos linfócitos e macrófagos, promovendo um aumento na concentração dessas células [23].

Os termos qualidade de vida na velhice, bem estar psicológico, bem estar percebido, bem estar subjetivo e envelhecimento satisfatório ou bem sucedido são expressôes tidas como equivalentes. Formam um construto global, referenciado a diversos pontos de vista sobre o envelhecimento como fato individual e social [3].

Quanto às mudanças percebidas, satisfação dos participantes deste estudo e avaliaçáo dos serviços prestados pela equipe destaca-se:

“Gastava na farmácia, R\$ 200,00 reais por mês, só de medicação para dores.” (NSA, F, 67)

"Melhorei, até o meu colesterol melhorou." (DRO, F, 75)

\footnotetext{
"Sempre nos recebem com carinho, com sorriso, assim sentimos que somos queridos e aqui podemos nos sentir como muitas das vezes não sentimos nem em nossos lares." (GBJ, F, 66)
}

"São todos excelentes, faço atividade física, informática, alongamento e vou ao médico." (LABA, F, 61)

"Todos excelentes na recepção, odontologia, inclusão digital, na musculação.” (SRMM, F, 60) 
"Paciência dos profissionais com as pessoas." (MTSSC, F, 62)

"Todos os profissionais do Planeta são atenciosos, não só com os usuários mais com todos que por aqui passam. Tenho profunda admiração por todos, inclusive pela seriedade das enfermeiras na avaliação se a gente pode ou não fazer exercícios na academia, na piscina....." (GRG, M,63)

"Luto contra a obesidade. Quanto a parte da assistência, todos são muito bons, o pessoal está sempre solicito (...) a nutricionista muito boa atenciosa ... (...) o cuidado das enfermeiras com a pressão da gente... pra gente não passar mal...(...) essa atenção que os profissionais dedicam a minha pessoa é fundamental.” (MA, M, 70)

Ao atender o idoso, a equipe de saúde deve estar atenta a uma série de alteraçôes físicas, psicológicas e sociais que normalmente ocorrem nessas pessoas, e que justificam um cuidado diferenciado [24]. Esses profissionais têm um importante papel com o idoso, pois se acredita que, através de uma relação empática, haja uma assistência humanizada e um comprometimento com o cuidado personalizado, garantindo o seu equilíbrio físico e emocional [2].

É importante reiterar que o conceito de qualidade de vida do idoso está relacionado à autoestima e ao bem estar pessoal e abrange uma série de aspectos como a capacidade funcional, o nível socioeconômico, o estado emocional, a interação social, a atividade intelectual, o autocuidado, o suporte familiar, o próprio estado de saúde, os valores culturais, éticos e a religiosidade, o estilo de vida, com atividades diárias e o ambiente em que se vive. $\mathrm{O}$ conceito de qualidade de vida, portanto, varia de autor para autor e, além disso, é um conceito subjetivo dependente do nível sociocultural, da faixa etária e das aspiraçóes pessoais do indivíduo $[25,26]$.

\section{Conclusão}

O estudo confirma que o implemento de unidades da administração pública, para atender a complexa realidade das pessoas idosas e suas necessidades de saúde, inclusão e cidadania, deve se caracterizar pela oferta de serviços e atendimentos profissionais focados na intersetorialidade subja- cente aos múltiplos elementos neles envolvidos, como forma de agilizar a resoluçáo dos mesmos com menos desgaste para seus usuários. Iniciativas dos gestores públicos fazem a diferença qualitativa para o amplo contingente de idosos da nossa sociedade.

Revela como as pessoas idosas vivem ociosas, deprimidas e sem perspectivas, quando gestores públicos perdem oportunidade de inovar no sentido de suprir a sociedade com programas capazes de transformar a vida dos idosos, como o Planeta Vida.

Demonstra que açóes intersetoriais contribuem substancialmente para êxito dos programas de educação para a saúde, considerando-se a multiplicidade de aspectos próprios do domínio de conhecimento dos profissionais que nelas atuam, uníssonos e focados na meta de atender as prioridades e necessidades da clientela. Além de reiterar aspectos subjacentes, como os benefícios advindos do bem estar dos idosos refletidos em menores despesas com procedimentos de maior complexidade em instituiçóes da rede de saúde do setor público ou privado.

Identifica substanciais mudanças registradas pelos idosos que transformaram o curso de suas vidas, em particular oportunidades que lhes dão acesso às informaçôes sobre promoção da saúde, prevenção de doenças e cuidados de enfermagem, bem como os habilitando para o acesso às informaçóes disponíveis no ciberespaço. Da mesma forma relevante para eles a prática orientada de exercícios físicos, a troca de experiências no convívio com seus pares, entre outras, essenciais ao envelhecimento saudável.

\section{Referências}

1. Berlezi EM, Eickhoff HM, Oliveira KR, Dallepiane LB, Perlini NMOG, Mafalda A et al. Programa de atenção ao idoso: relato de um modelo assistencial. Texto Contexto Enferm 2011;20(2):368-70.

2. Lima TJV, Arcieri RM, Garbin CAS, Moimaz SAS. Humanização na Atenção à Saúde do Idoso. Saúde Soc 2010;19(4):866-77.

3. Tahan J, Carvalho ACD. Reflexóes de idosos participantes de grupos de promoção de saúde acerca do envelhecimento e da qualidade de vida. Saúde Soc 2010;19(4):878-88.

4. Mendes R, Bogus CM, Akerman M. Agendas urbanas intersetoriais em quatro cidades de Sáo Paulo. Saúde Soc 2004; 13(1):47-55.

5. Machado WCA. Gestão Pública Municipal, Inclusão e Promoção da Saúde do Idoso e da Pessoa com Deficiência. Entre-Rios Jornal. 2011 junho 2; Coluna Sírius. (10 Caderno).

6. Silva ACS, Santos I. Promoção do autocuidado de idosos para o envelhecer saudável: aplicação da teoria de Nola Pender. Texto Contexto Enferm 2010;19(4):745-53. 
7. Veras R. Envelhecimento populacional contemporâneo: demandas, desafios e inovaçóes. Rev Saúde Pública 2009;43(3):548-54.

8. Lopes MSV, Saraiva KRO, Fernandes AFC, Ximenes LB. Análise do conceito de promoção da saúde. Texto Contexto Enferm 2010;19(3):461-8.

9. Sebold LF, Randuz V, Carvalho TE. Percepçóes sobre cuidar de si, promoção da saúde e sobrepeso entre acadêmicos de enfermagem. Esc Anna Nery Rev Enferm 2011;15(3):536-41.

10. Joia LC, Ruiz T, Donalisio MR. Condiçóes associadas ao grau de satisfação com a vida entre a população de idosos. Rev Saúde Pública 2007;41(1):131-8.

11. Ferreira CG, Alexandre TS, Lemos ND. Fatores associados à qualidade de vida de cuidadores de idosos em assistência domiciliária. Saúde Soc 2011;20(2):398-409.

12. Victora CG. Uma ciência replicante: a ausência de uma discussão sobre o método, a ética e o discurso. Saúde Soc 2011;20(1):104-12.

13. Lopes ALM, Fracolli LA. Revisão sistemática de literatura e metassíntese qualitativa: consideraçóes sobre sua aplicação na pesquisa em enfermagem. Texto Contexto Enferm 2008;17(4):771-8.

14. Brasil. Ministério da Saúde. Conselho Nacional de Saúde. Resolução No 196, de 10 de outubro de 1996: diretrizes e normas reguladoras de pesquisas envolvendo seres humanos. Brasília: Ministério da Saúde; 1996.

15. Bardin L. Análise de conteúdo. 3a ed. Lisboa: Ediçóes 70; 2004 .

16. Ramos M. Os sintomas depressivos e as relaçôes sociais na terceira idade. Rev Dep Psicol UFF 2007;19(2):397410.
17. Ramos M. Apoio social e saúde entre idosos. Sociologias 2002;7(2):156-75.

18. Di Nucci FRCF, Coimbra AMV, Neri AL, Yassuda MS. Ausência de relação entre hipertensão arterial sistêmica e desempenho cognitivo em idosos de uma comunidade. Rev Psiquiatr Clín (São Paulo) 2010;37(2):52-6.

19. Antunes HKM, Santos RF, Cassilhas R, Santos RVT, Bueno OFA, Mello MT. Exercício físico e função cognitiva: uma revisão. Rev Bras Med Esporte 2006;12(2):108-14.

20. Ministério da Saúde. Secretaria de Políticas de Saúde. Projeto promoçáo da saúde. As cartas de promoção da saúde. Brasília: Ministério da Saúde; 2002.

21. Oliveira DAAP, Gomes L, Oliveira RF. Prevalência de depressão em idosos que freqüentam centros de convivência. Rev Saúde Pública 2006;40(4):734-6.

22. Huang Y, Carpenter I. Identifying elderly depression using the Depression Rating Scale as part of comprehensive standardised care assessment in nursing homes. Aging Ment Health 2011;15(8):1045-51.

23. Moraes H, Deslandes A, Ferreira C, Pompeu FAMS, Ribeiro P, Laks J. O exercício físico no tratamento da depressão em idosos: revisão sistemática. Rev Psiquiatr Rio Gd Sul 2007; 29(1):70-9.

24. Wild D, Szczepura A, Nelson S. How social care staff working in residential homes perceive their professional status. Nurs Older People 2011;23(7):29-35.

25. Silva PCS, Terra FS, Graciano ADS, Magalhães ECR, Santos WAL. Elderly people practicing physical activity in social projects and life satisfaction. Rev Enferm UFPE online 2012;6(2):409-16.

26. Vecchia RD, Ruiz T, Bocchi SCM, Corrente JE. Qualidade de vida na terceira idade: um conceito subjetivo. Rev Bras Epidemiol 2005;8(3):246-52. 